\title{
Awareness of Breast Cancer among Female Students at Ain Shams University, Egypt
}

\author{
Dina N. K. Boulos ${ }^{1} \&$ Ramy R. Ghali ${ }^{2}$ \\ ${ }^{1}$ Community, Environmental and Occupational Medicine Department, Ain Shams University, Cairo, Egypt \\ ${ }^{2}$ Clinical Oncology Department, Ain Shams University, Cairo, Egypt \\ Correspondence: Dina N. K. Boulos, Community, Environmental and Occupational Medicine Department, Ain \\ Shams University, Cairo, Egypt. Tel: 2-010-0855-6234. E-mail: dnkamel@yahoo.com
}

\author{
Received: August 22, 2013 Accepted: September 20, 2013 Online Published: November 4, 2013 \\ doi:10.5539/gjhs.v6n1p154 URL: http://dx.doi.org/10.5539/gjhs.v6n1p154
}

\begin{abstract}
The present study aimed to determine knowledge of breast cancer risk factors, symptoms and early detection methods and to identify knowledge and practice of breast self-examination among Ain Shams University female students. This is a descriptive cross sectional study.Most study participants had low level of knowledge of breast cancer risk factors. The most widely known risk factors by the students were smoking $66.9 \%$, followed by radiation to the chest $63.7 \%$ and genetic factors $63.7 \%$. Most of the students $(81.6 \%)$ identified breast lump as a symptom for breast cancer. However, non lump symptoms were less known and less than half were aware of other warning signs. Mass media such as TV and/or radio were identified as the main source of information on breast cancer by $89.1 \%$ of students followed by relatives $39.2 \%$. Only $8.8 \%$ of students identified correctly the appropriate time to perform breast self examination and $1.3 \%$ reported performing it regularly every month. The most common reasons for not practicing BSE were" did not know how to perform it" $(47.7 \%)$ and lack of interest (35\%). The findings of this study showed that there is low level of knowledge on breast cancer risk factors, early warning signs and BSE among female university students and that only few students practice BSE monthly. Health care workers should develop effective breast health programs targeting youth to help females to gain healthy habits starting very early during their formative years.
\end{abstract}

Keywords: awareness, breast cancer, female university students

\section{Introduction}

Breast cancer is the most commonly diagnosed cancer and worldwide it is considered the leading cause of cancer death in females, accounting for $23 \%$ (1.38 million) of the total new cancer cases and $14 \%(458,400)$ of the total cancer deaths in 2008. Approximately half of the breast cancer cases and $60 \%$ of the deaths are estimated to take place in developing countries (Ferlay et al., 2008).

According to the official statistics of the Egyptian National Cancer Institute, breast cancer represents $18.9 \%$ of total cancer cases (35.1\% in women and 2.2\% in men) (Elatar, 2001). In Egypt, the median age at diagnosis for breast cancer is ten years younger than in the United States and Europe (Omar et al., 2003). Cancer in young is generally more aggressive and results in lower survival rates, making early detection even more crucial and emphasizing the importance to raise breast cancer awareness among young females (Rosenberg \& Levy- Schwartz, 2003; Sambanje \& Mafuvadze, 2012). Breast cancer mortality rates for African women are higher compared to women in Western countries (Kamangar, Dores, \& Anderson, 2006)

Although the importance of Breast Self Examination (BSE) is controversial (Hakama, Pukkala, Kallio, Godenhjelm, \& Svinhufvud, 1995; Thomas et al., 2002), the American Cancer Society recommends it for early detection of breast cancer as it assists women in two main ways; first by becoming familiar with both the appearance and the sense of their breasts and second by helping them to detect any changes in their breasts as soon as possible (American Cancer Society, 2008).

Although there were scarcity of studies on knowledge of breast cancer and practice of BSE among Egyptian females (Allam \& Abd Elaziz., 2012), to our knowledge there were no studies about the knowledge of breast cancer and practice of BSE among Egyptian female university students.

The present study aimed to determine knowledge of breast cancer risk factors, symptoms and early detection 
methods and to identify knowledge and practice of breast self-examination among Ain Shams University female students.

\section{Methods}

\subsection{Study Design}

This is a descriptive cross sectional study.

\subsection{Study Population}

Undergraduate students at non health related disciplines were included based on a belief that they possess less health information compared to the general public. The study sample included 543 female students at non health related disciplines, who were available on the day of data collection, who agreed to participate in the study and who returned a completely filled questionnaires (Response rate $=89.8 \%$ ).

\subsection{Study Tool}

A self administered questionnaire in Arabic language was distributed by fourth year medical students to study participants in order to clarify any item if needed A Clinical oncology consultant evaluated content and face validity of the questionnaire. Moreover, the questionnaire was pilot tested on 20 students (not included in study sample) to check the clarity of the questions. Results of the pilot test were used to adjust the wording of some questions in order to make them easier to understand. The Cronbach's alpha of study questionnaire is 0.805 .The questionnaire covered the following items

2.3.1 Part one: Socio-demographic data such as age, marital status, discipline, academic year.

\subsubsection{Part two:}

a. Knowledge of risk factors for breast cancer was determined with 13 questions. The answers were "true", "false" and "don't know". This part assessed the knowledge of breast cancer risk factors using the guidelines of the American Cancer Society (2008)

b. Knowledge of early warning signs, of methods of early detection and of different lines of treatment of breast cancer

\subsubsection{Part three:}

a. Knowledge of Breast Self Examination (BSE) term and correct time to perform it

b. Practicing BSE and reasons for not performing

c. Source of information on breast cancer

\subsection{Ethical Consideration}

Approval of study conduction was obtained from the ethical review Committee at the faculty of Medicine Ain Shams University. In addition, the purpose of the study was explained to all participants and confidentiality was assured, an oral informed consent was obtained and the survey tool was anonymous.

\subsection{Data Management and Statistical Analysis}

Data collected were revised, coded and computerized. Data entry using Statistical Package for Social Science (SPSS) version 18 was used. Frequency tables and a chart were utilized to describe nominal variables. Continuous variables were described using distributions, means and standard deviation.

\section{Results}

\subsection{Characteristics of Study Participants}

Participants in this study ranged in age from 17 to 23 years with a mean of $19.3(\mathrm{SD}=1.1)$. Of 543 participants $43.1 \%$ were students at commerce school. More than one third of study participants $36.7 \%$ were second year faculty students, $31.7 \%$ were fourth year and $25.7 \%$ were third year and only $5.9 \%$ were first year faculty students. The majority of participants $90.4 \%$ were single. Only $16.1 \%$ of students reported a family history of breast cancer. Nearly all study participants $98.7 \%$ believe that early detection improves treatment outcome and as many as $87.7 \%$ believe that there is an effective treatment for breast Cancer (Table 1). 
Table 1. Sample characteristics

\begin{tabular}{|c|c|c|}
\hline \multirow[t]{2}{*}{ Characteristics } & \multicolumn{2}{|l|}{ Frequency } \\
\hline & $\mathrm{N}=\mathbf{5 4 3}$ & Percent \\
\hline \multicolumn{3}{|l|}{ Age in years } \\
\hline Mean \pm SD & $19.26 \pm 1.1$ & \\
\hline Range & $(17-23)$ & \\
\hline \multicolumn{3}{|l|}{ Faculty } \\
\hline Literature & 146 & 26.9 \\
\hline Commerce & 234 & 43.1 \\
\hline Law & 55 & 10.1 \\
\hline Languages & 108 & 19.9 \\
\hline \multicolumn{3}{|l|}{ Faculty year } \\
\hline First & 32 & 5.9 \\
\hline Second & 99 & 36.7 \\
\hline Third & 140 & 25.7 \\
\hline Fourth & 172 & 31.7 \\
\hline \multicolumn{3}{|l|}{ Marital status } \\
\hline Single & 491 & 90.4 \\
\hline Engaged & 44 & 8.1 \\
\hline Married & 8 & 1.5 \\
\hline \multicolumn{3}{|c|}{ Family history of Breast Cancer } \\
\hline Yes & 88 & 16.2 \\
\hline No & 397 & 73.1 \\
\hline Do not know & 58 & 10.7 \\
\hline \multicolumn{3}{|c|}{ Believe that early detection improves treatment outcome } \\
\hline Yes & 536 & 98.7 \\
\hline No & 1 & 0.2 \\
\hline Do not Know & 6 & 1.1 \\
\hline \multicolumn{3}{|c|}{ Believe that there is an effective treatment for Breast Cancer } \\
\hline Yes & 477 & 87.7 \\
\hline No & 20 & 3.7 \\
\hline Do not Know & 46 & 8.5 \\
\hline
\end{tabular}

\subsection{Knowledge of Risk Factors}

Most students had low level of knowledge of breast cancer risk factors. The most widely known risk factors by the students were smoking $66.9 \%$, radiation to the chest $63.7 \%$ and genetic factors $63.7 \%$. Age at first full term pregnancy $>30$ years and never being pregnant were not known as risk factors for breast cancer by most of the students (Table 2). 
Table 2. Students' Knowledge of breast cancer risk factors

\begin{tabular}{lllllll}
\hline Risk Factors & \multicolumn{2}{l}{ True } & & False & & \multicolumn{2}{l}{ Do not know } \\
\cline { 2 - 7 } & $\mathbf{N}$ & $\mathbf{\%}$ & $\mathbf{N}$ & $\mathbf{\%}$ & $\mathbf{N}$ & $\mathbf{\%}$ \\
\hline Aging & 140 & 25.8 & 225 & 41.4 & 178 & 32.8 \\
High Fat Diet & 197 & 36.3 & 112 & 20.6 & 234 & 43.1 \\
Obesity & 124 & 22.8 & 176 & 32.4 & 243 & 44.8 \\
Smoking & 363 & 66.9 & 67 & 12.3 & 113 & 20.8 \\
Radiation to the chest & 346 & 63.7 & 38 & 7 & 159 & 29.3 \\
Alcohol & 246 & 45.3 & 75 & 13.8 & 222 & 40.9 \\
Oral contraceptive use & 105 & 19.3 & 126 & 23.2 & 312 & 57.5 \\
Never breast fed & 111 & 20.4 & 201 & 37.1 & 231 & 42.5 \\
Family history of breast cancer & 258 & 47.5 & 157 & 28.9 & 128 & 23.6 \\
Genetic Factors & 346 & 63.7 & 48 & 8.8 & 149 & 27.5 \\
Never being pregnant & 38 & 6.9 & 286 & 52.6 & 219 & 40.3 \\
Age at first full term pregnancy $>$ 30years & 32 & 5.9 & 201 & 37 & 310 & 57.1 \\
Early menarche (<12 years) & 40 & 7.4 & 160 & 29.4 & 343 & 63.2 \\
Late menopause (>55 years) & & & & & & \\
\hline
\end{tabular}

\subsection{Knowledge of Symptoms, Early Detection Measures and Lines of Treatment}

Most of the students $81.6 \%$ identified breast lump as a symptom for breast cancer. However, non lump symptoms were less known and less than half were aware of other warning signs such as change in shape/or retraction of nipple and bloody nipple discharge accounting for $25.6 \%$ and $24.7 \%$ respectively. Further, as many as $74.2 \%$ of students identified breast self examination as an early detection measure for breast cancer. The most widely known lines of treatment were surgery followed by chemotherapy accounting for $71.8 \%$ and $67.7 \%$ respectively (Table 3).

Table 3. Knowledge of warning signs, early detection and treatment of Breast cancer

\begin{tabular}{lllllll}
\hline Variables & True & & False & \multicolumn{2}{l}{ Do not know } \\
\cline { 2 - 6 } & N & \% & N & \% & N & \% \\
\hline Warning signs of breast cancer & & & & & & \\
Breast lump & 443 & 81.6 & 12 & 2.2 & 88 & 16.2 \\
Bloody nipple discharge & 134 & 24.7 & 61 & 11.2 & 348 & 64.1 \\
Pain in breast & 403 & 74.2 & 55 & 10.1 & 85 & 15.7 \\
Change in shape and/or breast size & 281 & 51.7 & 64 & 11.8 & 198 & 36.5 \\
Redness of breast skin & 189 & 34.8 & 61 & 11.2 & 293 & 54 \\
Change in shape and/or retraction of nipple & 139 & 25.6 & 42 & 7.7 & 362 & 66.7 \\
Early detection measures & & & & & & \\
Breast self examination & 403 & 74.2 & 44 & 8.1 & 96 & 17.7 \\
Mammogram & 283 & 52.1 & 31 & 5.7 & 229 & 42.2 \\
Breast U/S & 262 & 48.3 & 36 & 6.6 & 245 & 45.1 \\
Treatment of Breast Cancer & & & & & & \\
Surgery & 390 & 71.8 & 50 & 9.2 & 103 & 19 \\
Radiotherapy & 180 & 33.1 & 113 & 20.8 & 250 & 40.04 \\
Chemotherapy & 368 & 67.7 & 60 & 11.1 & 115 & 21.2 \\
Hormonal therapy & 94 & 17.3 & 118 & 21.7 & 331 & 61 \\
Targeted therapy & 88 & 16.2 & 79 & 14.6 & 376 & 69.2 \\
\hline
\end{tabular}

\subsection{Source of Health Information}

Mass media such as TV and/or radio were identified as the main source of information on breast cancer by $89.1 \%$ of students followed by relatives $39.2 \%$ (Figure1). 


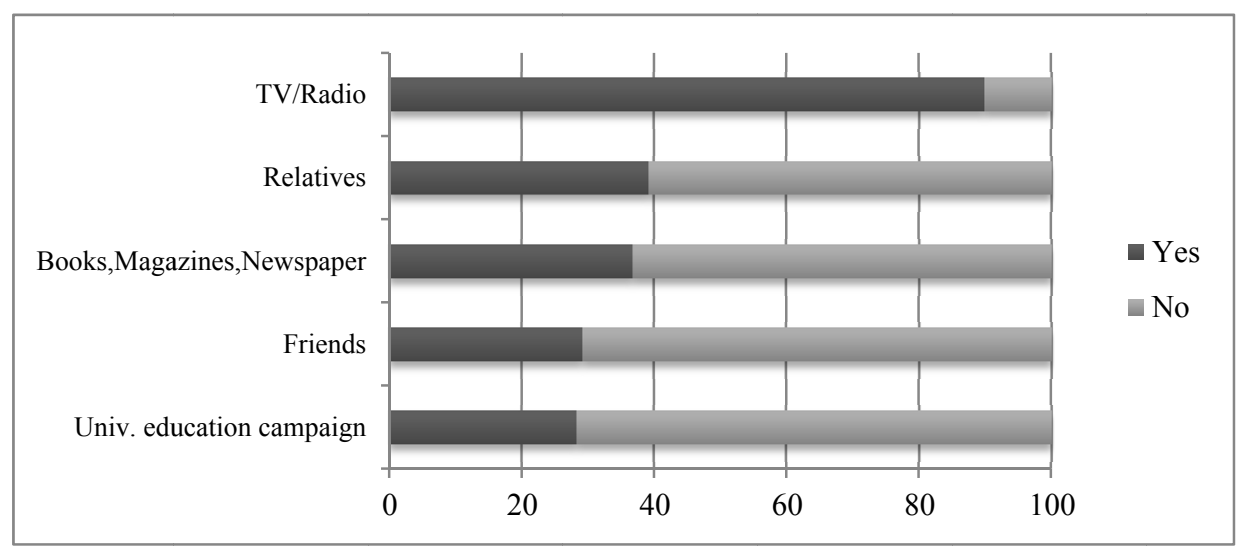

Figure 1. Sources of students' information

\subsection{Breast Self Examination}

More than half of the students (63.4\%) heard about BSE. Only $8.8 \%$ of students identified correctly the appropriate time to perform BSE. The percentage of students performing BSE regularly every month was $1.3 \%$ and $6.1 \%$ reported that they performed it irregularly. The most common reasons for not practicing BSE were "did not know how to perform it" (47.7\%) and lack of interest (35\%) (Table 4).

Table 4. Students' knowledge, performing and reasons for not performing BSE

\begin{tabular}{lll}
\hline Variables & $\mathbf{N}$ & $\mathbf{\%}$ \\
\hline Heard about BSE & 344 & 63.4 \\
Yes & 199 & 36.6 \\
No & & \\
\hline Knowledge of appropriate time for BSE & 344 & 8.8 \\
Correct answer & 75 & 13.8 \\
Incorrect Answer & 420 & 77.4 \\
Do not know & & \\
Performing BSE & 503 & 92.6 \\
No & 7 & 1.3 \\
Regular & 33 & 6.1 \\
Irregular & & \\
\hline Reason for not doing BSE & 240 & 47.7 \\
Do not know how to perform & 37 & 7.4 \\
Fear of positive finding & 30 & 5.9 \\
Forgetting & 176 & 35 \\
Not interested & 20 & 4 \\
Not sure of its ability in detection & & \\
\hline
\end{tabular}

\section{Discussion}

Informing youth about breast cancer is both a challenge and key investment in the health of future generations of women (Gürsoy et al., 2009) as it is well known that low cancer awareness contributes to delays in presentation of cancer symptoms, and subsequent diagnosis leading to less favorable outcomes (Nystrom, 2000).

In the current study more than half of the students (63.4\%) heard about BSE. This study showed that female university students may not have adequate knowledge about BSE as only $8.8 \%$ of the students had knowledge about appropriate time to perform BSE. Our findings are comparable to a study of Yemeni University students in which $76.9 \%$ of participants heard about BSE (Ahmed, 2010). The current study findings are lower than the following studies; Iheanacho, Ndu and Emenike (2013) in which 36\% of female undergraduate Nigerian students have knowledge on the appropriate time for BSE, Budden (1995) study revealing that $77 \%$ of the female students correctly identified the recommended time for BSE and Milaat (2000) reporting that $7.1 \%$ of 
secondary-school female nursing students had had knowledge about appropriate time for BSE. A cross-sectional study that included 718 female high school students in Turkey showed that only $37.9 \%$ of the students reported to hear about BSE and $13.2 \%$ provided correct response for its appropriate time (Karayur, Özmen, \& Çetinkaya, 2008).

In the current study only $1.3 \%$ practice BSE regularly every month and $6.1 \%$ reported that they performed it irregularly. Our findings are lower than (Karayur et al., 2008) study in which $6.7 \%$ of high school students in Turkey were performing BSE monthly and $20.3 \%$ of the students were performing BSE irregularly. In other studies the percentage of monthly BSE performance have been found to be 3.4\% among teenagers (Ludwick \& Gaczkowski, 2001), 17.4\% among female Yemeni university students (Ahmed, 2010), 13\% of the first year of nursing students (Budden, 1999), 14.8\% among students aged 17 to 30 years in Europe (Wardle et al., 1995), 37\% among female university nursing students in Australia (Budden, 1995). The above mentioned studies revealed the low prevalence of youth monthly performing BSE all over the world.

Studies from Egypt have revealed that the percentage of older women performing BSE monthly ranged from 2.7\% to $18.8 \%$ (Abdel Fattah et al., 2000; El Shamy \& Shoma, 2010).

It is anticipated that a higher percentage of women in older age groups perform BSE because they are at higher risk of breast cancer. However, studies from Egypt have shown low percentages of both young and older women performing BSE. This may be due to the fact that health education programs organized to increase breast health awareness are not satisfactory. Such education programs should start very early in the formative years.

In the present study mass media such as TV and/or radio were identified as the main source of information on breast cancer by $89.1 \%$ of students followed by relatives $39.2 \%$ and $36.8 \%$ acknowledged books, magazines and newspapers as the leading source of information. This is consistent with Iheanacho et al. (2013) study showing that majority of the students had acquired information about breast cancer, its risk factors and BSE from sources such as media (68\%), from books (68\%), school (lectures, friends) $(66 \%)$ and from health care providers $(64 \%)$.

Similarly media was acknowledged as the main source of information on breast cancer by $48.6 \%$ of female high school students in Turkey while $44.4 \%$ of the sample mentioned health professionals as a source of information (Karayur et al., 2008).In another study of Chinese women aged 20 years or greater mass media, such as newspaper and television, was acknowledged by $73.2 \%$ as the major information source on breast cancer, followed by doctors or health care providers as identified by 16.1\% (Yan, 2009). Likewise (81.6 \%) of Yemeni university students mentioned mass media as the first source of information about breast cancer (Ahmed, 2010). These findings indicate that media continue to be one of the most important sources of information about breast cancer and BSE.

Not knowing how to perform BSE was the primary reason for not practicing BSE as reported by $47.7 \%$ of Nigerian female students, lack of interest was identified by $35 \%$ and only $7.4 \%$ mentioned fear of a positive finding as a reason (Iheanacho et al., 2013). This agrees with a Yemeni study in which $55.9 \%$ of students mentioned lack of knowledge about technique of BSE as a barrier for not practicing BSE (Ahmed, 2010). Similarly the most common reasons for not doing BSE stated by Turkish high school students were "not knowing how to perform BSE" (98.5\%), "not expecting to get breast cancer" (45.6\%) and "fear of discovering a breast lump" (8.8\%) (Karayur et al., 2008).

In the current study nearly all study participants (98.7\%) believe that early detection improves treatment outcome and as many as $\mathbf{8 7 . 7 \%}$ believe that there is an effective treatment for breast Cancer. However, most students had poor knowledge of breast cancer risk factors. The most widely known risk factors by the students were smoking (66.9\%), radiation to the chest $(63.7 \%)$, genetic factors $(63.7 \%)$ and Family history of breast cancer $(47.5 \%)$. Age at first full term pregnancy $>30$ years and never being pregnant were not known as risk factors for breast cancer by most of the study participants.

Similarly a study carried out to determine the awareness of breast cancer risk factors and practice of breast selfexamination among female students of the University of Nigeria Enugu Campus showed that the only risk factors that are widely known are family history of breast cancer $(50 \%)$, and tobacco smoking $(36 \%)$. The findings also showed that very few students had knowledge of other risk factors (obesity, alcohol intake, early menarche, nulliparity, breastfeeding for at least 18 months as possible risk factors for breast cancer (Iheanacho et al., 2013).

Likewise the most widely known risk factors by Turkish high school students were personal history of breast cancer $(68.7 \%)$ and family history of breast cancer $(67.0 \%)$. In other words, students know that breast cancer was associated with genetic factors (Karayur et al., 2008). 
Most of the students $(81.6 \%)$ in the present study identified breast lump as a symptom for breast cancer followed by pain in breast as reported by $74.2 \%$. However they were less knowledgeable about non lump symptoms and less than half were aware of other warning signs such as change in shape/or retraction of nipple and bloody nipple discharge accounting for $25.6 \%$ and $24.7 \%$ respectively. Further, as many as $74.2 \%$ of students identified breast self- examination as an early detection measure for breast cancer. The most widely known lines of treatment were surgery followed by chemotherapy accounting for $71.8 \%$ and $67.7 \%$ respectively.

In concordance with the current study a cross-sectional survey of Angola university students using a self-administered questionnaire, showed that almost all study participants (80\%) reported that breast lumps that are cancerous would be painful (Sambanje \& Mafuvadze, 2005). Powe et al. (2005) reported that association of pain with cancer is a common myth and in fact pain is not necessarily a warning sign of breast cancer as many persons associate pain with the occurrence of cancer and the fact is pain is not necessarily an early sign of breast cancer.

Knowledge of symptoms and methods of diagnosis of breast cancer was mostly above (60\%)among nurses working in a general hospital in Lagos, Nigeria and the most widely reported symptom identified by( $93.6 \%$ ) of the $\mathrm{m}$ was breast lump (Odusanya \& Tayo, 2001).

\section{Study Limitations}

The present research is as a cross sectional study on female university students in one of the most eminent governmental universities in the capital of Egypt as a result it does not represent Egyptian female youth population as a whole also the results of the current study do not represent the entire population of Egyptian female university students all over Egypt. In addition, the study participants were relatively homogenous as a group so sociodemographic comparisons were not performed.

\section{Conclusion}

Health behaviors acquired early in life have an influence on future health. The findings of this study showed that there is low level of knowledge on breast cancer risk factors, early warning signs and BSE among female Ain Shams University students and that only few students practice BSE monthly. There is a need to raise the knowledge of university students about the risks of breast cancer and benefits of early detection. Health care workers should develop effective breast health programs targeting youth to help females to gain healthy habits starting very early during their formative years.

\section{References}

Abdel -Fattah, M., Zaki, A., Bassili, A., el- Shazly \& M., Tognoni, G. (2000). Breast self examination practice and its impact on breast cancer diagnosis in Alexandria, Egypt. East Mediterr Health J., 6(1), 34-40. PMid:11370338

Ahmed, B. A. (2010). Awareness and practice of breast cancer and breast-self examination among university students in Yemen. Asian Pacific Journal of Cancer Prevention, 11(1), 101-105.

Allam, M. F., \& Abd Elaziz, K. M. (2012). Evaluation of the level of knowledge of Egyptian women of breast cancer and its risk factors. A cross sectional study. Prev med hyg, 53, 195-198.

American Cancer Society. (2008). Breast Cancer Facts and Figures. Retrieved from http://www.cancer.org/downloads/STT/CAFF2005BrFacspdf2005.pdf

Budden, L. (1995). Young women's breast self-examination knowledge and practice. $J$ Community Health Nurs, 12, 23-32. http://dx.doi.org/10.1207/s15327655jchn1201_3

Budden, L. (1999). Student nurses' breast self-examination health beliefs, attitudes, knowledge, and performance during the first year of a preregistration degree program. Cancer Nurs, 22, 430-437. http://dx.doi.org/10.1097/00002820-199912000-00006

Elatar, I. (2001). Cancer Registration, NCI Egypt; National Cancer Institute: Cairo, Egypt, 2002. Available online at: http://www.nci.edu.eg/Journal/nci2001\%20.pdf accessed 10/01/2013

Elshamy, K. F., \& Shoma, A. M. (2010). Knowledge and Practice of Breast Cancer Screening Among Egyptian Nurses. Afr J Haematol Oncol, 1(4), 122-128.

Ferlay, J., Shin, H. R., Bray, F., Forman, D., Mathers, C. D., \& Parkin, D. (2008). GLOBOCAN, Cancer Incidence and MortalityWorldwide: IARC CancerBase No. 10. Lyon, France: International Agency for Research on Cancer; 2010. Retrieved from http://globocan.iarc.fr

Gürsoy, A., Yiğitbaş, C., Yılmaz, F., Erdöl, H., Bulut, H., \& Mumcu, H. (2009). The effect of peer education on 
university students' knowledge of breast self-examination and health beliefs. The Journal of Breast Health, 5(3), 135-40.

Hakama, M., Pukkala, E., Kallio, M., Godenhjelm, K., \& Svinhufvud, U. (1995). Effectiveness of screening for breast cancer in women under 50 years at entry: The Kokta Pilot Project in Finland. Int J Cancer, 63, 55-57. http://dx.doi.org/10.1002/ijc.2910630111

Iheanacho, P., Ndu, A., \& Emenike, A. D. (2013). Awareness of breast cancer risk factors and practice of breast self examination among female undergraduates in university of Nigeria Enugu campus. Open Journal of Nursing, 3, 147-152. http://dx.doi.org/10.4236/ojn.2013.31019

Kamangar F, Dores GM, Anderson WF. (2006). Patterns of cancer incidence, mortality, and prevalence across five continents: defining priorities to reduce cancer disparities in different geographic regions of the world. Journal of Clinical Oncology, 24(14), 2137-2150. http://dx.doi.org/10.1200/JCO.2005.05.2308

Karayur, O., Özmen, D., \& Çetinkaya, A. C. (2008). Awareness of breast cancer risk factors and practice of breast self examination among high school students in Turkey. BMC Public Health, $8,359$. http://dx.doi.org/10.1186/1471-2458-8-359

Ludwick, R., \& Gaczkowski, S. (2001). Breast self-exams by teenagers. Cancer Nurs, 24, $315-319$. http://dx.doi.org/10.1097/00002820-200108000-00013

Milaat, W. A. (2000). Knowledge of secondary-school female students on breast cancer and breast self-examination in Jeddah, Saudi Arabia. East Mediterr Health J, 6, 338-344.

Nystrom, L. (2000). How effective is screening for breast cancer? BMJ, 32, $647-649$. http://dx.doi.org/10.1136/bmj.321.7262.647

Odusanya, O. O., \& Tayo, O. O. (2001). Breast Cancer Knowledge, Attitudes and Practice among Nurses in Lagos, Nigeria. Acta Oncologica, 40(7), 844-848. http://dx.doi.org/10.1080/02841860152703472

Omar, S., Khaled, H., Gaafar, R., Zekry, A. R., Eissa, S., \& El-Khatib, O. (2003). Breast cancer in Egypt: A review of disease presentation and detection strategies. East Mediterr Health J., 9, 448-463.

Powe, B. D., Underwood, S., Canales, M., \& Finnie, R. (2005). Perceptions about breast cancer among college students: Implications for nursing education. J Nurs Educ, 44(6), 257-65.

Rosenberg, R., \& Levy- Schwartz, R. (2003). Breast cancer in women younger than 40 years. Int J Fertil Womens Med, 48, 200-205.

Sambanje, M. N., \& Mafuvadze, B. (2012). Breast cancer knowledge and awareness among university students in Angola. Pan Afr Med J, 11, 70.

Thomas, D. B., Gao, D. L., Ray, R. M., Wang, W. W., Allison, C. J., Chen F. L., ... Self, S. G. (2002). Randomized trial of breast self-examination in Shanghai: final results. J Natl Cancer Inst, 94, 1445-1457. http://dx.doi.org/10.1093/jnci/94.19.1445

Wardle, J., Steptoe, A., Smith, H., Groll-Knapp, E., Koller, M., Smith, D. \& Brodziak, A. (1995). Breast self examination: attitudes and practices among young women in Europe. Eur J Cancer Prev, 4, 61-68. http://dx.doi.org/10.1097/00008469-199502000-00005

Yan, Y. Y. (2009). Breast Cancer: Knowledge and Perceptions of Chinese Women in Hong Kong. Global Journal of Health Science, 1(2), 97-105.

\section{Copyrights}

Copyright for this article is retained by the author(s), with first publication rights granted to the journal.

This is an open-access article distributed under the terms and conditions of the Creative Commons Attribution license (http://creativecommons.org/licenses/by/3.0/). 